for the identification of indifferent streptococci. J Clin Pathol 1980;33:47-52.

${ }^{17}$ Colman G, Williams REO. Taxonomy of some human viridans streptococci. In: Wannamaker LW, Matsen $\mathrm{JM}$, eds. Streptococci and streptococcal diseases: recognition, understanding and management. New York and London: Academic Press, 1972:281-99.

Requests for reprints to: Mr GS Tillotson, Department of Surgery and Microbiology, University of Manchester School of Medicine, Hope Hospital, Salford M6 8HD, England.

\section{Use of FITC-protein A in place of fluorescein-conjugated anti- gammaglobulins for rapid virus diagnosis by immunofluorescence}

DJ WOOD, G CORBITT North Manchester Regional Virus Laboratory, Booth Hall Hospital, Manchester, M9 $2 A A$

The indirect immunofluorescent antibody technique is widely used in the rapid diagnosis of virus infection by demonstration of virus antigens in both clinical specimens and cultured cells. ${ }^{1}$ It requires a specific antiviral antiserum, usually raised by animal immunisation, and an appropriate fluoresceinlinked anti-species globulin. Various animals are often used as sources of antiviral antisera and therefore corresponding anti-species conjugates are required. The number of second stage reagents should be kept to a minimum since each needs to be tested against the full range of virus-infected and uninfected cell cultures together with clinical specimens before routine use. ${ }^{2}$ Also the wrong antispecies conjugate may inadvertantly be used.

Protein-A binds specifically to the $\mathrm{Fc}$ region of IgG (with the exception of sub-class 3) of many animal species ${ }^{3}$ and is available commercially as a fluorescein-linked reagent. It has previously been used in veterinary work for identifying virus isolates by immunofluorescence and, when conjugated with peroxidase, for assaying anti-viral antibodies in animal sera from different animal species by means of ELISA techniques. ${ }^{4}$ It was therefore of interest to test FITC-protein A for its suitability as a routine reagent.

\section{Material and methods}

VIRUS-INFECTED MONOLAYERS

Confluent monolayers of cells, grown in 12-well PTFE-coated slides (CA Handley Ltd, Essex), were infected with virus diluted in maintenance medium. When approximately $10 \%$ of the cell sheet showed evidence of virus growth, slides were washed in phosphate-buffered saline (PBS) and fixed in cold, dry acetone for $10 \mathrm{~min}$.

Alternatively, viruses were grown in tube cell cultures. When growth of virus could be seen in some $10 \%$ of the cell sheet, cells were removed from the glass with trypsin, washed and resuspended in

Accepted for publication 12 October 1981 
PBS, spotted on to PTFE-coated slides, air-dried and fixed as previously described.

All such slides were stored at $-40^{\circ} \mathrm{C}$ for future use.

NASO-PHARYNGEAL ASPIRATES

Secretions were suspended in virus transport medium by gentle pipetting and then centrifuged at $800 \mathrm{~g}$ for $10 \mathrm{~min}$ at $4^{\circ} \mathrm{C}$. The cell deposit was washed twice with PBS and the recovered cells again resuspended in PBS. Drops of this suspension were placed on PTFE-coated slides and the preparations dried and fixed as described above.

\section{IMMUNOLOGICAL REAGENTS}

Rabbit sera-anti-influenza A, anti-influenza B (Standards Laboratory for Serological Reagents, Colindale), anti-herpes virus simplex (MerciaBrocades Ltd).

Bovine sera-anti-respiratory syncytial virus, antiparainfluenzavirus type 3 (Wellcome Laboratories Ltd).

Sheep serum-anti-measlesvirus (Evans Biologicals Ltd).

G. pig serum-anti-adenovirus (hyperimmunisation with adenovirus type 5 hexon antigen purified by ion-exchange chromatography ${ }^{5}$ ).

FITC-conjugated anti-species sera-sheep antibovine, sheep anti-rabbit, sheep anti-guinea pig, rabbit anti-sheep (Wellcome Laboratories Ltd). FITC-protein A (Pharmacia UK Ltd) made up to
$1 \mathrm{mg} / \mathrm{ml}$ in PBS. The anti-guinea pig and anti-sheep conjugates were absorbed with a mixture of $\mathrm{HEF} /$ HEp 2 cells.

Each virus antiserum was tested in chessboarded fashion on virus-infected cells using both the appropriate anti-species globulin conjugate and FITCprotein $\mathrm{A}$. The degree of specific fluorescence was scored on a three point scale $(+$ to +++$)$ and the optimum fluorescent antibody titre (OFAT) was regarded as corresponding to the highest dilution of serum giving a +++ reading. The degree of nonspecific background fluorescence attributable to each conjugate was also evaluated on a similar scale. After determining the OFAT, virus-specific anti-sera were used with either anti-species globulin or protein-A conjugates to stain nasopharyngeal aspirates.

\section{Results}

The results (Table 1) show that FITC-protein A reacts with the immunoglobulins from three of the four species of animals used to raise antisera. The OFAT of the anti-virus serum was reduced in all cases but this was compensated by the improvement in the quality of fluorescence seen with rabbit and guinea pig sera. The reagent gave a poor reaction with bovine immunoglobulins and apparently failed to react with sheep anti-measles immunoglobulins (Table 2).

The improvement in the quality of the fluorescence

Table 1 Results of antiserum chessboard titrations

\begin{tabular}{|c|c|c|c|c|c|}
\hline \multirow[t]{2}{*}{ Virus antiserum } & \multirow[t]{2}{*}{ Animal immunised } & \multicolumn{2}{|l|}{$O F A T$ virus antiserum } & \multicolumn{2}{|c|}{$O F A T$ conjugate } \\
\hline & & With anti-species conjugate & $\begin{array}{l}\text { With FITC- } \\
\text { protein } A\end{array}$ & Anti-species & Protein $A$ \\
\hline Influenzavirus group A & Rabbit & 20 & 5 & 20 & 20 \\
\hline Influenzavirus group B & Rabbit & 80 & 10 & 20 & 10 \\
\hline Herpesvirus hominis & Rabbit & 80 & 10 & 20 & 10 \\
\hline Respiratory syncytial virus & Bovine & 10 & 2 & 80 & 5 \\
\hline Parainfluenzavirus type 3 & Bovine & 4 & 1 & 80 & 5 \\
\hline Adenovirus & Guinea pig & 20 & 10 & 10 & 10 \\
\hline Measlesvirus & Sheep & 4 & $<1$ & 20 & $<2$ \\
\hline
\end{tabular}

All titres expressed as reciprocals of the dilution.

Table 2 Degree of fluorescence shown by the various virus antiserum/conjugate combinations

\begin{tabular}{|c|c|c|c|c|}
\hline \multirow[t]{2}{*}{ Origin of antiserum } & \multicolumn{2}{|l|}{ Specific fluorescence } & \multicolumn{2}{|c|}{ Non-specific fluorescence } \\
\hline & Anti-species conjugate & FITC-protein $A$ & Anti-species conjugate & FITC-protein $A$ \\
\hline Rabbit & $+\div+$ & +++ & + & - \\
\hline Bovine & +++ & + & - & - \\
\hline Guinea pig & ++ & $++t$ & +++ & - \\
\hline Guinea pig (absorbed) & ++ & +++ & ++ & - \\
\hline Sheep & ++ & - & $+t+$ & - \\
\hline Sheep (absorbed) & ++ & - & + & - \\
\hline
\end{tabular}


obtained with FITC-protein A was due to the absence of background fluorescence on both infected

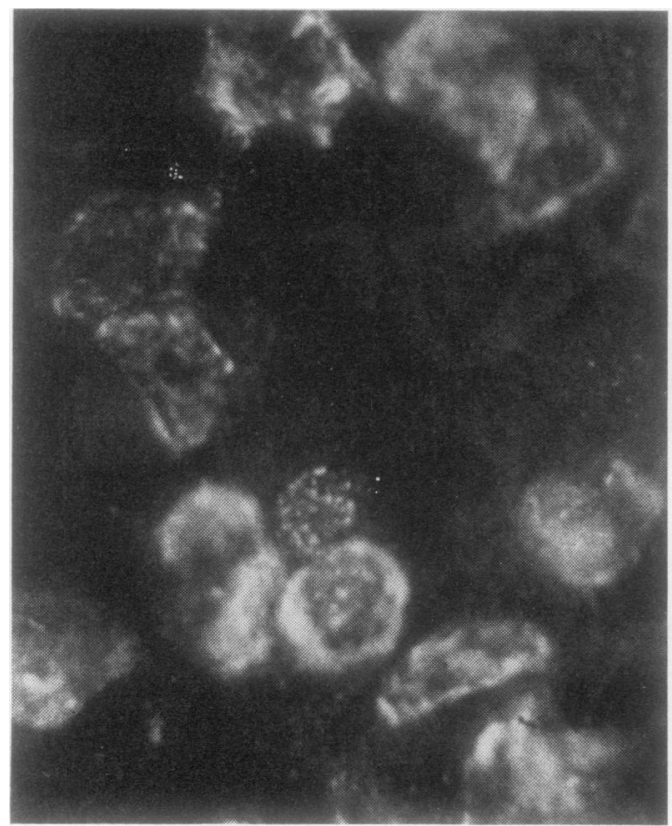

la cell cultures and clinical specimens. Background fluorescence was present with most anti-species

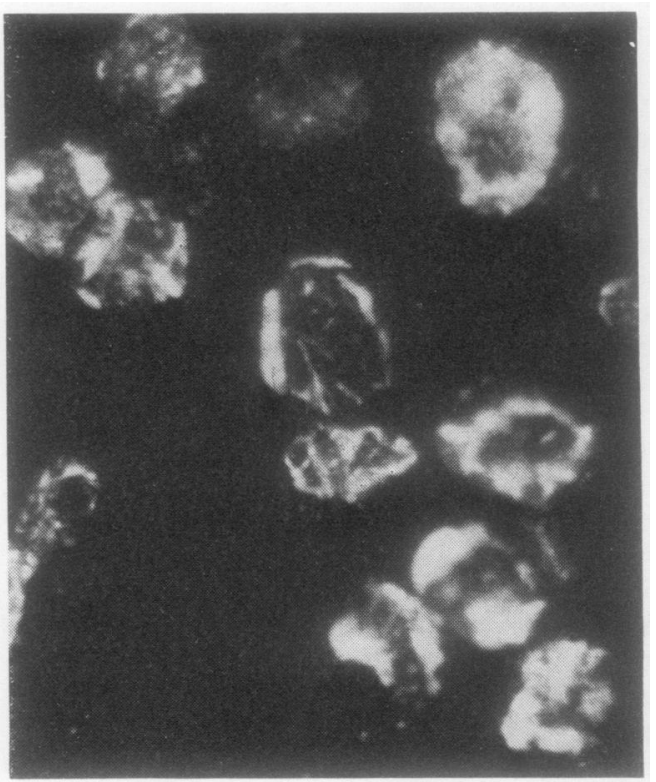

$1 \mathrm{~b}$

Fig. 1 Adenovirus 5 antigen in virus-infected Hep 2 cells stained by the indirect fluorescent antibody technique. (a) FITC-anti-species conjugate. (b) FITC-protein A, showing absence of hackground fuorescence.

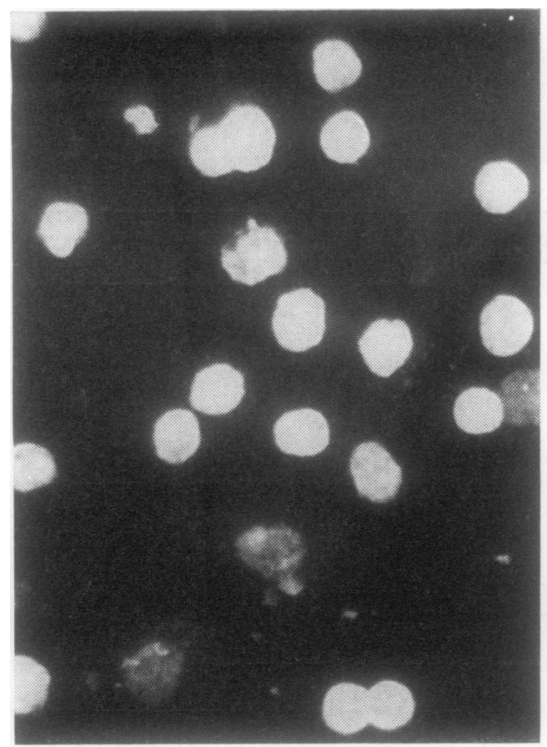

$2 \mathrm{a}$

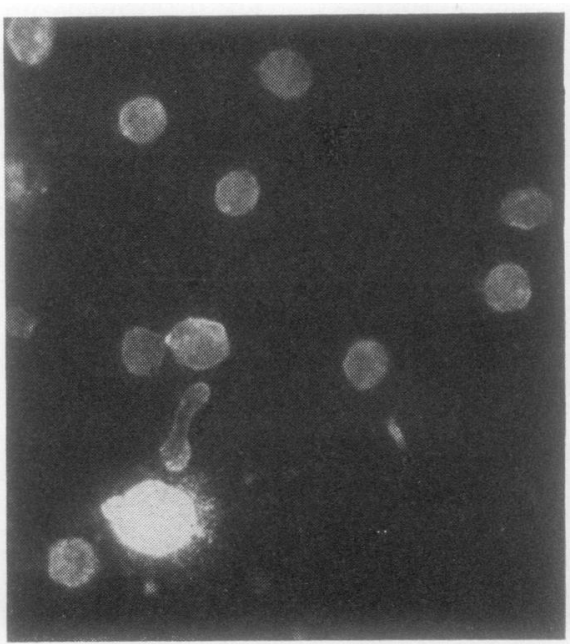

$2 b$

Fig. 2 Adenovirus 3 antigen in cells of nasopharyngeal secretion stained by the indirect immunofluorescent antibody. technique. (a) FITC-anti-species conjugate, showing unwanted fluorescence in all cells. (b) FITC-protein A, showing absence of unwanted fluorescence. 
conjugates even after absorption. Thus, specific fluorescence with FITC-protein A is remarkably well shown in specimens in which reaction takes place. The differences are illustrated in Figs 1 and 2.

\section{Discussion}

The results clearly show that FITC-protein A reacts with the immunoglobulins of some of the animal species employed to raise the routine antiviral antisera used in our laboratory. There appears to be no reaction with sheep immunoglobulins and with those of the other species tested, the OFAT of the virus antiserum is less than that obtained when the anti-species conjugate is used as a second layer of the test. This inevitably means that, when using FITCprotein $\mathbf{A}$ as the second stage reagent in an indirect immunofluorescence test, it is necessary to use much lower dilutions of the specific anti-viral antisera. This finding is presumably related to the fact that the reagent reacts only with certain sub-classes of IgG whereas the anti-species conjugates have, in all cases, been raised against whole globulin preparations. It is also apparent that the differences recorded for the OFAT are not constant for antiviral sera prepared in the same animal species. This probably reflects the differing immunoglobulins in antisera raised in individual animals within the same breeding line and even sometimes between successive bleeds from the same animal.

The results also show that background fluorescence is completely absent in our system when FITCprotein A is used. Anti-species conjugates frequently present serious problems of unwanted fluorescence and require absorption with tissue extracts in order to reduce or abolish this. Use of FITC-protein A can therefore not only improve results but also reduce the work load.

Unwanted fluorescence can be due to a number of factors, ${ }^{2}$ but our results suggest that it is related mainly to the anti-species conjugate. Absence of unwanted fluorescence with FITC-protein A is probably due to the fact that the protein $\mathrm{A}$ has been isolated and purified by affinity chromatography before conjugation whereas the anti-species conjugates probably contain substantial amounts of conjugated serum proteins other than immunoglobulins. Despite the lack of background staining with FITC-protein A, the intensity of the specific staining seen with bovine antisera is still less than that obtained with the anti-species conjugate. These findings, together with the absence of reaction with sheep immunoglobulins, are disappointing since FITC-protein A cannot therefore be used as a universal second stage reagent in those laboratories in which anti-viral antisera raised in either cattle or sheep are used.

The poor reaction of protein A with immunoglobulins of ruminants has been noted by other workers. ${ }^{3}$ In the same study it was shown that protein A reacts well with immunoglobulins from other mammalian species not used in our study (horse, goat, pig, dog and cat).

Another feature of the use of FITC-protein A is that, at no stage did the reagent appear to react with immunoglobulin bound to $F c$ receptors on herpes-infected cells. This warrants further investigation.

The fact that protein $\mathrm{A}$ can be obtained in a very pure form points to an important step forward in the quality of reagents for immunofluorescence techniques. We have now introduced the reagent into routine use for much of our rapid diagnostic work.

This work formed part of a much larger investigation into viral infections in leukaemic children and has been financed mainly by the Leukaemia Research Fund for which we express our gratitude.

\section{References}

1 Gardner PS. Rapid virus diagnosis. J Gen Virol 1977;36: 1-29.

${ }^{2}$ Gardner PS, McQuillan J. Rapid Virus Diagnosisapplication of immunofluorescence. 2nd ed. London: Butterworth, 1980.

${ }^{3}$ Goudswaard J, van der Donk JA, Noordzij A, van Dam RH, Vaerman JP. Protein A reactivity of various mammalian immunoglobulins. Scand J Immunol 1978;8: 21-8.

${ }^{4}$ Bommeli W, Kihm U, Zindel F, Fey H. Enzymelinked immunoassay and fluorescent antibody techniques in the diagnosis of viral diseases using staphylococcal protein-A instead of anti-gammaglobulins. Vet Immunol and Immunopathol 1980;1:179-93.

${ }^{5}$ Spence D, Kenny G, McLure AR, MacFarlane DE, Sommerville RG. The preparation of an antiserum to adenovirus group (hexon) antigen to be used for immunofluorescent detection of infection with different adenoviruses. Arch ges Virusforsch 1971;34:340-5.

Requests for reprints to: Mr DJ Wood, North Manchester Regional Virus Laboratory, Booth Hall Hospital, Manchester M9 2AA, England. 